\title{
Um Olhar Psicanalítico sobre a Amamentação de Bebês Prematuros na UTI Neonatal
}

\author{
A Psychoanalytic view at Breastfeeding Premature Babies in the Neonatal ICU
}

\section{Una Mirada Psicoanalítica para la Lactancia de los Bebés Prematuros en la UCI Neonatal}

\author{
Andréa Leão Leonardo-Pereira de Freitas ${ }^{1}$ \\ Eliana Rigotto Lazzarini \\ Eliane Maria Fleury Seidl \\ Universidade de Brasilia (UnB)
}

\begin{abstract}
Resumo
Este artigo consiste em um estudo teórico sobre a complexidade dos fatores físicos, psíquicos e socioculturais implicados na vivência das mães de bebês prematuros em relação à amamentação, na unidade de terapia intensiva neonatal (UTIN). Busca-se problematizar a prática de prescrever a amamentação às gestantes e lactantes, sem levar em consideração aspectos subjetivos e inconscientes que influenciarão na adesão a esta recomendação. Os discursos dos profissionais de saúde, apoiados no excesso de informações científicas sobre a amamentação, bem como argumentos moralistas que circunscrevem este tema, não são suficientes para que se estabeleça o aleitamento materno. A amamentação vai além de um processo meramente fisiológico, exigindo da mulher condições psíquicas favoráveis para que ela possa desempenhar o papel de nutriz. Pode haver casos em que não amamentar a criança no seio traga mais benefícios à saúde mental da díade, sem que isso signifique ser a mãe menos zelosa ou cuidadosa do que as demais.

Palavras-chave: prematuridade, amamentação, psicanálise, equipe de saúde, UTI neonatal
\end{abstract}

\begin{abstract}
This paper consists of a theoretical study on the complexity of the physical, psychic, and sociocultural factors involved in the premature-baby-mother's breastfeeding experience, in the neonatal intensive care unit (NICU). It looks to problematize the practice of prescribing breastfeeding to pregnant and lactating women without considering subjective and unconscious aspects that will influence adherence to this recommendation. The speech of health professionals, supported by the excess of scientific information about breastfeeding, as well as moralistic arguments that circumscribe this theme, are not enough for breastfeeding to be established. Breastfeeding goes beyond a purely physiological process, requiring favorable psychic conditions from the woman so that she can play the role of a nursing mother. There may be cases in which not breastfeeding the child brings more benefits to the mental health of the dyad, without this being the mother less zealous or careful than the others.
\end{abstract}

Keywords: prematurity, breastfeeding, psychoanalysis, healthcare professionals, neonatal ICU

\section{Resumen}

Este artículo consiste en un estudio teórico sobre la complejidad de los factores físicos, psicológicos y socioculturales involucrados en la experiencia de las madres de bebés prematuros en relación con la lactancia materna, en la unidad de cuidados intensivos neonatales (UCIN). Buscamos problematizar la práctica de prescribir la lactancia materna a mujeres embarazadas y lactantes, sin tener en cuenta los aspectos subjetivos e inconscientes que influirán en el cumplimiento de esta recomendación. Los discursos de los profesionales de la salud, respaldados por el exceso de información científica sobre la lactancia materna, así como los argumentos moralistas que circunscriben este tema, no son suficientes para establecer la lactancia materna. La lactancia materna va más allá de un proceso puramente fisiológico, y requiere condiciones psicológicas favorables de las mujeres para que puedan desempeñar el papel de una madre lactante. Puede haber casos en los que no amamantar al niño traiga más beneficios para la salud mental de la díada, sin que esto signifique que la madre sea negligente o menos cuidadosa que las demás.

Palabras clave: prematuridad, lactancia materna, psicoanálisis, equipo de salud, UCI neonatal

\footnotetext{
${ }^{1}$ Endereço para contato: SQS 216, bloco D, apt. 502, Asa Sul, Brasília-DF. Cep: 70295-040. Telefone: (61) 99993-0402. E-mail: leao.freitas@uol.com.br
} 


\section{Introdução}

Este artigo tem o objetivo de apresentar um estudo teórico sobre a vivência de mães de bebês prematuros em relação à amamentação na Unidade de Terapia Intensiva (UTI) neonatal, utilizando como base teórica a psicanálise, com orientação winnicottiana. O contexto do estudo consiste na UTI neonatal, uma vez que é comum os bebês prematuros ficarem internados por um período neste ambiente, devido a algum comprometimento orgânico em virtude do seu nascimento antecipado.

O autor de referência deste trabalho é o médico pediatra e psicanalista inglês Donald W. Winnicott (1896-1971), que se dedicou a descrever as relações iniciais entre a criança e sua mãe, discutindo as especificidades da amamentação em textos publicados originalmente em 1945 e 1968. Entretanto serão também mencionados ao longo do texto autores psicanalistas de outras abordagens, tais como os franceses Jacques Lacan e Françoise Dolto e pesquisadores das demais áreas do conhecimento que estudam esta temática, como os médicos brasileiros Luís Alberto M. Tavares e Marcus Renato de Carvalho.

As demandas que a amamentação de bebês prematuros no contexto da UTI neonatal impõem à mãe tendem a afetar a equipe de saúde que a acompanha, tornando necessárias intervenções multidisciplinares. A interface psicanálise-pediatria e áreas afins pode favorecer o estabelecimento de um vínculo satisfatório entre a díade mãe-bebê, facilitando ou não o estabelecimento do aleitamento, a depender de fatores físicos da mulher até aqueles relacionados a questões psíquicas inconscientes e as próprias características do bebê (Feliciano \& Souza, 2011).

Analisar esse tema sob a luz da psicanálise possibilita, além de uma melhor compreensão sobre a construção do vínculo afetivo entre o bebê e sua mãe, o fomento da produção científica sobre o nascimento prematuro e a amamentação e, principalmente, leva os profissionais da saúde a refletirem sobre novas maneiras de olhar e se relacionar com essas mães, que precisam receber uma assistência humanizada no pós-parto.

O que é proeminente na questão da prematuridade é o cuidado para que as intervenções atravessem o processo de subjetivação, contribuindo para a construção do vínculo afetivo entre mãe-bebê e permitindo que as palavras sejam veiculadas. A psicanálise se ocupará das questões relativas à reverberação psíquica que esse nascimento inesperado pode gerar no psiquismo da mãe e na constituição da subjetividade do bebê.

O desafio, no caso específico do bebê prematuro, é sustentar sua dimensão de sujeito em um momento em que sua sobrevivência depende de ser tomado como objeto de cuidados (Zornig, Morsch, \& Braga, 2004).

Este artigo não pretende defender ou desencorajar a amamentação. Aqui importa refletir sobre como a imposição deste ato pode ameaçar a subjetividade da mãe que amamenta, desconsiderando o seu desejo, sua história de vida e as questões subjetivas e inconscientes que permeiam o seu desejo de desempenhar a função de nutriz. Além disso, essa obrigatoriedade de amamentar também pode colocar sob ameaça a emergência psíquica do bebê, que é constituída a partir da voz, do olhar, do desejo e da relação com a mãe. Entretanto a amamentação realizada em decorrência de uma obrigação imposta, como ato puramente mecânico, não garante o investimento da fala e do olhar materno que são estruturantes na formação da personalidade do sujeito. 
É possível questionar se a sociedade ocidental em que vivemos não atribui à maternidade e à amamentação um lugar idealizado, associado à ideia de transmissão de amor e carinho, em que o aspecto orgânico se sobrepõe ao psíquico. Algumas obras de arte reproduzem esse pensamento, como "A maternidade", de Pablo Picasso, pintada em 1905, ou "Mãe e Filho", de Pierre Auguste Renoir de 1892, por exemplo. Nestas obras, o seio da mulher é tomado como nobre e virtuoso, escondendo as angústias que circundam algumas mães, para quem o aleitamento é uma vivência dolorosa e conturbada.

Para problematizarmos as vivências das mães de bebês prematuros no que tange à amamentação, inicialmente focalizaremos as singularidades do nascimento prematuro, para depois abordarmos como se dá a amamentação destes bebês e os fatores que estão relacionados a esse processo. Refletir sobre a vivência de mães de bebês prematuros em relação ao aleitamento materno nos leva a questionar se insistir com a gestante que a amamentação é um ato amoroso pode transmitir a ideia de que a mãe que não conseguiu amamentar teve dificuldades em amar o seu bebê, sendo uma mãe menos "generosa", menos mãe, como defende laconelli (2011).

\section{O Nascimento Prematuro}

É considerado como recém-nascido prematuro aquele que nasce antes da mãe completar 37 semanas de gestação (Brasil, 2006). As nomenclaturas feto extraútero, feto recém-nascido ou recém-nascido de risco são empregadas também na área médica para se referir a esse bebê (Fabre-Grenet, 1997). O termo recém-nascido pré-termo (RN-PT) é usado considerando o fato de o bebê ser maduro para a sua idade e para o estágio do desenvolvimento em que se encontra (Gandra, 1998). Freitas e Gutierrez (2010) optaram pelo uso da nomenclatura pré-termo, por priorizar a questão da maturidade física do bebê condizente à idade gestacional no momento do nascimento. No entanto optamos aqui pela utilização do termo prematuro, em vez de pré-termo, para enfatizar a dependência absoluta do bebê humano no nascimento em relação aos cuidados da figura materna, para garantir tanto a sua sobrevivência física quanto a sua constituição psíquica. Lacan (1966/1998, p. 100) fala em "prematuração específica do nascimento no homem". Contudo estamos nos referindo neste trabalho a um bebê que nasce ainda mais prematuro do que os outros, dependendo para sobreviver não apenas dos cuidados maternos, mas também dos recursos tecnológicos desenvolvidos pela ciência.

O nascimento prematuro pode ser considerado um evento traumático tanto para a mãe como para o bebê, pois consiste em um excesso de tensão vindo do exterior, aliado a uma falta de recurso do sujeito para responder a tal excesso. Para Rosa (2016, p. 47-48), a irrupção do traumático aparece como ". . . a desorganização subjetiva decorrente da emergência daquilo que está fora do sentido e da significação". Um evento é tanto mais traumático quanto maior for a sua ancoragem na fantasia, que pode ocorrer, por exemplo, quando uma mãe mantém uma ambivalência em relação à gestação e se culpa pelo nascimento prematuro do filho (Agman, Druon, \& Frichet, 1999).

Quando a criança nasce prematura, não há tempo para ocorrer a transformação necessária das representações maternas, o que geralmente acontece no último trimestre de gestação e protege a mãe (e, consequentemente, o bebê) de possíveis conflitos entre o bebê real e o bebê imaginado na mente da mãe (Brazelton, 1994, p. 425). 
O nascimento da criança ocorre em um estágio de representações mentais, mencionado por Nadia Bruschweiler-Stern (1997), em que o bebê seria imaginado como ativo, gratificante, vigoroso, como um bebê de três meses de vida pós-natal. Isso se torna mais difícil no caso do nascimento prematuro, já que os pais terão de fazer esse ajuste em suas representações, o que pode gerar um estresse adicional para eles, uma vez que, junto a isso, estarão preocupados com a sobrevivência e o bem-estar do filho.

As relações iniciais entre mãe-bebê, nos primeiros anos de vida, vão influenciar significativamente as relações sociais futuras desse sujeito (Brazelton, 1994; Klaus \& Kennell, 1992; Mathelin, 1999; Stern, 1997; Winnicott, 1999). Diante disso, emerge a importância de pensarmos neste grupo de bebês que, em virtude de seu nascimento inesperado, são precocemente afastados de suas mães até que ocorra a estabilização do seu estado clínico. A partir da década de 1960, houve um crescimento no processo de humanização na Medicina, especialmente na área de Neonatologia, entendendo-se que o distanciamento mãe-bebê comprometeria a formação do vínculo e, consequentemente, a constituição psíquica do bebê (Góes, 1999). Estudos mostraram que, nos casos em que a separação física é muito longa, o estabelecimento de laços afetivos entre mãe-bebê prematuro se torna difícil, podendo gerar um "estranhamento" entre esta dupla, de tal modo que a mãe poderá até mesmo não o reconhecer como sendo seu filho (Klaus \& Kennell, 1992). Sendo assim, faz-se indispensável o contato físico precoce entre mãe-bebê prematuro, quando ele ainda estiver internado no ambiente da UTI neonatal, tão logo o seu estado clínico permita tal aproximação.

A participação da mãe nos cuidados do bebê internado na UTI neonatal, como nas trocas de fralda, na administração da dieta por sonda e, principalmente, quando ela é autorizada a segurá-lo no colo, mesmo que por curtos períodos, contribui para que os sentimentos vivenciados no início da internação se transformem, na medida em que tais atitudes representam o desempenho do seu papel materno e aumentam a sua autoconfiança. O bebê deixa de ser percebido como aquele que pertence à equipe (Souza, Araújo, Costa, Carvalho, \& Silva, 2009).

No que se refere ao bebê, os esforços empreendidos no nascimento prematuro não devem assegurar apenas a normalização das suas funções vitais e não devem perder de vista a reanimação do desejo de viver que habita o sujeito. Nesses casos de prematuridade, o desamparo e a impotência, que caracterizam a espécie humana em seus primórdios de vida, encontram-se redobrados.

O fato de a mãe poder ver, tocar e cuidar do bebê contribuirá para o fortalecimento do vínculo afetivo após o nascimento. Klaus, Kennell e Klaus (2000) afirmam que:

Se um bebê pequeno e prematuro é tocado, embalado, acariciado, abraçado diariamente ou se conversamos com ele durante a sua permanência na enfermaria, ele poderá apresentar menos pausas na respiração, ganho de peso e um progresso mais rápido em algumas áreas de maior funcionamento cerebral que pode persistir por meses, depois da alta hospitalar. (Klaus et al., 2000, p. 127)

O bebê prematuro, assim como o recém-nascido a termo, reconhece também a voz de sua mãe. Quando isso ocorre, a criança agitada se acalma, relaxa, abre os olhos e procura de onde vem a voz materna. O apaziguamento do bebê se traduz pelas modificações dos ritmos cardíaco e respiratório, observados no cardiorrespirógrafo (Couronne, 1997). 
A voz materna cumpre a função de "cordão umbilical sonoro", permitindo a continuidade entre o período intrauterino e o neonatal, e, caso o pai também tenha conversado com o filho durante a gestação, haverá por parte do bebê o reconhecimento da sua voz (Braga \& Morsch, 2003, p. 60).

A psicanalista Wilheim (1997) comenta também alguns recursos importantes que podem ser utilizados para amenizar a separação prematura do bebê com o corpo de sua mãe, endossando o uso de gravações com músicas que esta costumava ouvir ou cantar durante a gravidez ou a introdução na incubadora de uma peça de sua roupa, impregnada com o seu cheiro.

O nascimento prematuro muitas vezes dificulta que os pais ofereçam ao bebê aquilo que Winnicott (1983) chamou de holding (o ato de segurar) e handling (o ato de manipular o bebê). No entanto estar na UTI neonatal não significa que os pais não possam segurá-lo ou manuseá-lo. Os pais devem aprender a identificar os sinais emitidos pelo bebê, a partir da compreensão da sua linguagem, buscando ajustar os seus gestos e manuseio a ele, de modo que o recém-nascido possa desenvolver-se física e psicologicamente. No intuito de ajudá-los a traduzir os movimentos do bebê em palavras, Lima (2008, p. 135) propõe uma intervenção que consiste em especularizar o discurso entre mãe e filho: ela tanto pode ser dirigida ao bebê falando o manhês como para a mãe falando como uma criança pequena, delineando alguns picos prosódicos.

Inicialmente, é frequente que as mães se aproximem do bebê prematuro de um modo singular e diferente do descrito por Winnicott (1978, p. 493) como "preocupação materna primária", que consiste em uma condição psicológica da mãe muito especial, quase uma doença, caracterizada por um estado de sensibilidade aumentada durante, e especialmente, no final da gravidez, o qual continua por algumas semanas após o nascimento da criança. O autor afirma que tanto para a mulher atingir essa "doença normal" como para sair dela é necessário que esta seja saudável, ou seja, esteja gozando de um bom estado mental. A pergunta que fazemos e que já fora formulada por Mathelin (1999, p. 67) é a seguinte: "Como pode uma mulher estar em bom estado quando seu filho em perigo lhe é retirado ao nascimento?"

Em um primeiro momento, a mãe assume uma modalidade interativa, a qual Agman et al. (1999, p. 27) chamaram de "preocupação médico-primária", que a permite se aproximar, conhecer e envolver-se com o bebê, por meio das informações técnicas e das condições clínicas dele. A mãe ocupa uma função mais médica do que maternal, mas, na verdade, por trás dessa atitude de apropriar-se dos códigos de comunicação dos cuidadores profissionais, ela está demonstrando disponibilidade para interagir com o filho, participando das decisões sobre as condutas terapêuticas que serão tomadas.

Morsch e Braga (2007, p. 628) alertam para o cuidado em não se adotar uma perspectiva valorativa ao considerar a "preocupação médico-primária" como uma recusa da função materna. Essa postura da mãe de empoderamento (empowerment), diferente do que é idealmente aceito por alguns profissionais da equipe de saúde, pode gerar desconforto, pelo fato de não admitirem que a mãe possa adotar uma posição mais assertiva dentro da UTI neonatal, contrariando a esperada fragilidade do seu papel enquanto parturiente prematura. Não há um tempo determinado para que a mãe consiga transpor esse modelo de maternagem, conseguindo relacionar-se com o bebê para além das suas condições clínicas. 
A "preocupação médico-primária" apenas consiste em um mecanismo de transição utilizado pela mãe na busca de um encontro que foi antecipado.

\section{Amamentação e Nascimento Prematuro}

A amamentação é uma vivência biopsicossocial do ciclo sexual/reprodutivo da mulher, mais especificamente o puerpério (Carvalho \& Tavares, 2010). Do ponto de vista psicossomático, emoções como medo e ansiedade, bem como fadiga e dor, interferem negativamente na ejeção do leite, por meio da inibição hipotalâmica da secreção de ocitocina e da liberação da adrenalina. Assim, devemos pensar em como se dá a vivência da amamentação dessas mães que, segundo a psicanalista Mathelin (1999), são narcisicamente feridas pela prematuridade.

Arias (2018) comenta que pais orgulhosos de seu filho o cobrirão de palavras, porém o mesmo não ocorre quando o nascimento da criança quebra o narcisismo parental, contrapondo-se ao projeto idealizado por eles. Apesar da autora referir-se ao nascimento de uma criança com síndrome de Down, é possível fazer uma analogia ao nascimento prematuro, uma vez que em ambas as situações há em pauta a diferença, e a criança é marcada por algo da ordem do real.

Atualmente, há um consenso de que a recomendação geral para o cuidado com qualquer bebê prematuro requer o aleitamento materno. Se para um bebê nascido em tempo normal a amamentação é importante, para um prematuro é fundamental. Conforme várias organizações, como a Academia Americana de Pediatria, o Fundo das Nações Unidas para a Infância (UNICEF), o Ministério da Saúde e a Sociedade Brasileira de Pediatria, o leite materno é o melhor alimento para o recém-nascido prematuro. Havia controvérsias sobre a adequação desse leite para este bebê, contudo, nos últimos anos, cresceu a indicação do leite da própria mãe para o recém-nascido prematuro, por se tratar de um fluido dinâmico, que se adapta às necessidades da criança. A composição do leite da mãe de um bebê prematuro muda durante o dia e no curso da amamentação para nutri-lo melhor. Além disso, a amamentação estimula o desenvolvimento psicomotor do bebê e o protege contra infecções (Brasil, 2009).

Segundo Maldonado (2017), a amamentação é muito mais do que um processo fisiológico de alimentar o bebê, pois consiste em uma oportunidade de aprofundar o contato mãe-filho e suavizar a separação provocada pelo parto.

Ao ser amamentado, o bebê literalmente volta para o corpo da mãe e reelabora aos poucos a separação, quando o desmame não é precoce nem abrupto. Cada mamada é um encontro pele a pele, em que o afeto se expressa pelo olhar, pelos movimentos rítmicos do corpo do bebê e pelo prazer sensual estimulado pela sucção, o que inclui a amamentação no espectro da sexualidade da mulher. (Maldonado, 2017, p. 147)

No entanto, para que a amamentação seja bem-sucedida, é necessário que vários fatores socioculturais, físicos e psicológicos sejam atendidos. Na impossibilidade de as mães amamentarem o recém-nascido prematuro assim que ele nasce, a equipe de saúde as encaminham para o banco de leite da maternidade, para que elas façam a ordenha manual do leite, a fim de que este possa ser oferecido ao bebê, seja qual for o método de alimentação que ele esteja recebendo. 
Os profissionais da saúde incentivam o aleitamento materno dos bebês de modo geral, especialmente do recém-nascido prematuro, por conhecerem os benefícios que esse alimento é capaz de proporcionar a eles, porém é possível questionar se a simples transmissão desses conhecimentos para as mães, sob a forma de um discurso prescritivo, de caráter moralizante, não acaba potencializando o sentimento de culpa na mulher, por não ter levado a gestação a termo.

Winnicott (2017) afirma que, após o nascimento do bebê, a mãe encontra-se em um período em que está inclinada a depender de alguém e sensível às opiniões de qualquer mulher que esteja por perto, seja sua própria mãe, seja a sogra ou a enfermeira. Neste momento, ela dificilmente será capaz de reagir contra o discurso intrusivo dessas pessoas, especialmente as mães primíparas, que não se sentem seguras em relação a sua capacidade de amamentar. Apesar de o autor reconhecer o valor positivo da amamentação como uma experiência rica, intensa e poderosa na formação do vínculo entre mãe-bebê, admite a complexidade que circunda essa vivência.

O autor discorda da obrigatoriedade de a mãe amamentar, pois reconhece as questões subjetivas e pessoais que estão envolvidas. Tais dificuldades podem estar ligadas a conflitos internos ou a experiências pelas quais as mães passaram na infância, que escapam ao controle consciente. É preferível, nesses casos, o uso da alimentação artificial à experiência do bebê ser pego por uma mãe angustiada e deprimida, cuja amamentação será falseada. Insistir na amamentação de um bebê cuja mãe não é capaz de investi-lo narcisicamente e não consegue dirigir um olhar interessado a ele é colocá-lo em uma situação de risco em relação a sua constituição psíquica, o que se verifica por eventuais distúrbios do sono, atrasos no crescimento e desenvolvimento, síndromes autísticas, entre outros. Nesses casos, a criança se sentirá aliviada com a introdução da mamadeira, e a mãe poderá desenvolver outro tipo de intimidade física com o bebê.

Feliciano e Souza (2011) relacionam a possibilidade de amamentar, bem como a capacidade emocional do pai em dar suporte a essa vivência entre mãe/bebê, às representações psíquicas construídas ao longo da história e pré-história de cada um dos pais, com seus objetos primordiais, cujos traços inconscientes podem atrapalhar ou contribuir nesse momento.

Langer (1981) aborda também as razões inconscientes que impedem algumas mães de amamentarem os seus filhos, todas relacionadas com a insatisfação oral destas mulheres, que as farão ou apresentar tendências agressivas infantis dirigidas para a própria mãe ou rejeitar a maternidade, pelo desejo que possuem de permanecer em uma posição receptiva e infantil. A autora defende também que uma mãe que segura o bebê em seus braços e the oferece a mamadeira lentamente, e com carinho, significará menos frustração do que o seio dado friamente.

Middlemore (1974) afirma que a atitude das mães para superar as dificuldades impostas pela amamentação é favorável, baseada principalmente em fantasias orais benignas, ao contrário daquelas cujas fantasias sobre a amamentação são muito ríspidas. A maneira pela qual o bebê irá ou não sugar o seio ativará fantasias orais maternas que poderão contribuir para o abandono ou o sucesso da amamentação, na medida em que serão mais ou menos toleráveis para cada mulher. A autora observou que as mães de alguns bebês inertes temiam que eles morressem ao seio durante o sono, enquanto que, para outras mães, o manejo de 
um bebê inquieto e excitado, que pode machucar e morder o seio, pode provocar fantasias inconscientes que tornam a amamentação intolerável.

A criança, para ter boa saúde, necessita do que Dolto (1950/2007) chamou de clima afetivo harmonioso no momento da alimentação. A criança é capaz de sentir o estado emocional da mãe, se ela está ansiosa, apressada ou tensa, em vez de estar calma e afetuosamente atenta ao filho, e pode sofrer por contágio com o clima nervoso materno. "Ela bebe a angústia com o leite" (Dolto, 1950/2007, p. 69).

Winnicott (1999) concorda que há um certo exagero quanto ao uso do jargão "seio bom" (p. 21) para indicar uma maternidade ou paternidade satisfatórias, vez que o holding e o handling são mais importantes do que a experiência concreta da amamentação. Há casos em que a amamentação parece ter sido bem-sucedida e, no entanto, ocorreram deficiências no processo de desenvolvimento do bebê, bem como em sua capacidade de se relacionar com as pessoas e utilizar objetos, resultado de ter sido segurado e manipulado de modo insatisfatório.

Apesar de a amamentação favorecer a formação do vínculo afetivo entre mãe-bebê, não é possível afirmar que apenas pelo fato de a mãe estar amamentando a criança terá um bom desenvolvimento, pois, segundo Fiori (1981),

O relacionamento com a mãe é primordialmente qualitativo. Não importa apenas dar o seio. O que importa é como o seio é dado, como as solicitações paralelas da criança são atendidas, ou seja, não se está apenas incorporando o leite da mãe, mas também sua voz, seus embalos, suas carícias. (Fiori, 1981, p. 38)

A amamentação pode também ser relacionada às vivências da gestação, do parto e pós-parto. Dependendo de como a mãe vivenciou esses papéis de gestante e parturiente e de como está passando pelo puerpério, ela terá mais ou menos dificuldades de desenvolver o papel de mãe-nutriz. Existem também outros fatores, além dos psicológicos, que interferem na capacidade de a mãe conseguir ou não desempenhar esse papel, tais como os socioculturais e físicos.

\section{Amamentação: Aspectos Históricos e Barreiras}

No Brasil, a valorização da amamentação é recente, iniciando-se na década de 1980, quando amamentar tornou-se sinônimo de ser boa mãe. No Brasil colonial, a amamentação pela escrava era comum, tendo a amamentação pela ama de leite perdurado até o final do século XIX (Carvalho \& Tavares, 2010).

Na França, o aleitamento mercenário era uma prática corriqueira até o século XVIII: as mulheres das classes abastadas contratavam amas em domicílio e as de classes populares enviavam seus filhos para os campos, para serem amamentados por camponesas (Badinter, 1985). Nos dias atuais, apesar de a Organização Mundial da Saúde recomendar e dos médicos incentivarem a amamentação exclusiva até o sexto mês de vida, complementando à alimentação da criança até dois anos ou mais, Carvalho e Tavares (2010) questionam as condições sociais concretas que a sociedade oferece às mães para que consigam realizar esse projeto.

No que se refere às limitações das condições de saúde, algumas doenças como a aids e o câncer impedem a mãe de amamentar o filho, assim como, em certos casos, o bebê 
necessita melhorar o seu estado clínico para conseguir sugar o seio, como muitas vezes ocorre com aqueles que nascem prematuramente. Nessas situações específicas, é importante que a mãe saiba que mais importante do que o leite materno é oferecer ao bebê o carinho, aconchego e estimulação, indispensáveis para o seu bom desenvolvimento, como já foi comentado acima, a partir dos estudos de Winnicott (1999).

Dois estudos podem ser citados para ilustrar esse fato: o primeiro deles é o de Harlow e Suomi (1970), realizado com primatas, em que se verificou, entre outros resultados relevantes, que a alimentação não é tão essencial quanto o contato físico com o corpo da mãe, uma vez que os pesquisadores observaram que os macacos preferiam a mãe substituta de pano em vez da de arame, quando foi introduzido um aparelho mecânico como estímulo provocador de medo, mesmo que fosse esta última a oferecer-lhe o leite. O segundo exemplo consiste no caso das mulheres da tribo dos Mundugumor, pesquisada pela antropóloga Margaret Mead, que aleitam seus filhos, porém sem carinho, resultando em pessoas altamente agressivas consigo mesmas e com os outros, além de evidenciar a existência de um alto índice de suicídio entre eles (Carvalho \& Tavares, 2010, p. 170).

\section{Vivência Materna e Amamentação de Bebês Prematuros}

Amamentar nem sempre é uma tarefa simples, embora seja muitas vezes considerada como um processo fácil e instintivo. No caso de bebês prematuros, amamentar é bastante desafiador, por eles não apresentarem um controle adequado da sucção/deglutição/respiração e pela sua aparência geral de extrema fragilidade, fazendo com que as mães cheguem a acreditar que não são capazes de amamentá-los (Soares, Novaes, Araújo, \& Vieira, 2016).

Na pesquisa realizada por Baeta (2011, p. 158), a autora comenta que os pais são fortemente atingidos pelo nascimento prematuro do filho e refere-se a esse momento como um "encontro faltoso", em que o desamparo da criança não encontra refúgio no seio materno, pois a mãe vê-se impossibilitada de exercer a sua função.

A mulher idealiza o nascimento de um bebê apto a mamar diretamente em seu seio, sendo capaz de garantir o crescimento e desenvolvimento do filho. No entanto, na maioria das vezes, não é assim que acontece: a alimentação do recém-nascido prematuro geralmente é feita por meio de sondas orogástricas. Nesse momento, as mães vivenciam uma prática totalmente diferente do que imaginavam durante a gestação (Gorgulho \& Pacheco, 2008).

Nos casos em que tanto a mãe como o bebê que nasce a termo gozam de boa saúde, a alimentação constitui apenas uma parte da relação entre a díade, porém, no nascimento prematuro, esta assume uma importância maior, uma vez que o que está em jogo são tanto questões da ordem do real, ligadas à sobrevivência do bebê (como ganho de peso), quanto questões relacionadas ao simbólico, que demandarão da mãe uma ressignificação da sua relação com um bebê tão diferente do que ela esperava. Para isso, ela terá de fazer um luto do filho idealizado como perfeito e se tornar uma mãe suficientemente boa para esse bebê real. Essa relação é dialética, pois, se, por um lado, existe uma mãe, que terá de fazer todo um ajuste nas suas representações mentais para lidar com a realidade, por outro, existe o bebê, que terá também o seu modo próprio de interagir e que facilitará ou não o investimento libidinal materno.

O bebê deixou de ser visto como um ser passivo a partir do final da década de 1960; antes disso, ele podia ser metaforicamente comparado a um pedaço de argila em que os 
pais imprimiam facilmente a sua marca. Com o novo paradigma sobre quem é o bebê e a sua capacidade de influenciar as atitudes e os comportamentos dos pais, estudos puderam apontar para a relação entre as características pessoais de cada bebê e os diferentes tipos de maternagem oferecidos em resposta, por sua mãe (Lebovici, 1987).

Esse fato não seria diferente com o bebê prematuro, pois cada um reage de um modo peculiar. Alguns são hiper-reativos, hiperexcitáveis, quando apresentam descargas motoras ou gritos sob a menor estimulação. Nesses casos, mudanças um pouco mais bruscas de posição do bebê ou estímulos sonoros poderão ter um efeito desorganizador no bebê prematuro. Outros são apáticos, sonolentos, quase não reagem às tentativas dos pais de comunicação com eles. Existem, ainda, aqueles que se encontram entre esses dois extremos, mostrando capacidades de regulação de seus estados de vigilância e de interação com os pais, orientando-se por suas vozes ou mantendo uma certa duração de olhares mútuos (Mazet \& Stoleru, 1990).

Mesmo os bebês prematuros estáveis clinicamente e liberados para sugar o seio materno têm uma sucção débil, cansam-se e podem engasgar com mais facilidade, sendo necessário que as mães tenham paciência e compreendam as limitações de seus filhos, além de receberem todo o esclarecimento e apoio da equipe de saúde (Gorgulho \& Pacheco, 2008).

Diante disso, devemos reconhecer a dialética complexa que se dá na relação mãe-bebê, pois, se, de um lado, há questões subjetivas ligadas ao inconsciente da mãe, por outro, há o bebê real que vai interagir com ela de maneira única, sendo capaz de reativar vivências infantis prazerosas ou conturbadas que poderão favorecer ou dificultar a amamentação.

É importante a participação ativa das mães no aleitamento de seus bebês, por meio da gavagem, quando a alimentação é oferecida pela sonda, ou de outro método utilizado pela equipe. Mesmo que inicialmente elas não possam amamentar seus filhos, devem ser estimuladas a ordenhar o leite materno, não sendo privadas de nutri-los. O suporte oferecido às mães facilitará a lactação, que está relacionada ao aspecto emocional. Uma mãe calma, confiante e tranquila terá mais facilidade em produzir leite do que aquela deprimida, tensa e ansiosa (Baltazar, Gomes, \& Cardoso, 2010). Portanto cabe à equipe estar atenta aos sinais emocionais que a mãe emite, a fim de encorajá-la a aleitar, propiciando um ambiente favorável a esse processo.

Na situação específica do nascimento prematuro, fala-se em encorajar, apoiar e esclarecer as mães no sentido de aleitarem seus filhos, pois, além de se reconhecer a importância da amamentação como uma vivência íntima e primordial na formação do vínculo mãe-bebê, reconhecem-se as consequências do impacto deste nascimento no psiquismo da mãe, que também pode ser considerada prematura. É evidente que, se existirem conflitos pessoais anteriores a este acontecimento, ". . . a teoria precisa ser flexível, de tal forma que qualquer fato clínico possa, se necessário, modificar a afirmação teórica” (Winnicott, 1999, p. 19).

\section{Considerações Finais}

Diante de fatores psíquicos, socioculturais e físicos implicados na amamentação, a vivência de ter a gravidez interrompida de modo inesperado, devido ao parto prematuro, pode interferir negativamente no aleitamento materno. Uma diversidade de fatores interfere no sucesso ou fracasso da amamentação, inexistindo causa unívoca que determine o resultado 
desse fenômeno complexo. Antes de atribuir-se à mãe a responsabilidade pelo desmame precoce, devem ser observados os fatores físicos, sociais, culturais e psíquicos que fazem parte do contexto de vida dessa mulher.

Não é aconselhável que o profissional de saúde tenha uma noção preconcebida daquilo que deve ser feito pela mãe no que diz respeito à amamentação, pois isto pode gerar consequências desastrosas para ambos, mãe e bebê, o que implicaria na imposição do discurso médico sobre o sujeito e a eliminação da sua subjetividade. Não é raro que o discurso destes profissionais esteja embasado no modelo clássico e positivista de ciência, favorecendo a crença de que um saber construído é válido para todos, privilegiando o que é visível e objetivo em detrimento daquilo que não é palpável, ou seja, o inconsciente. Desse modo, quando o sujeito não é colocado em posição de fala e assume uma postura de passividade perante o discurso médico, a sua subjetividade é posta em risco.

A amamentação feita de uma maneira imposta, sem que a mulher se sinta confortável nesta tarefa, pode ser prejudicial, em termos psíquicos, tanto para ela quanto para o bebê. Winnicott (1999) criticou aquilo que chamou de propaganda a favor da amamentação, enfatizando a importância de a mãe oferecer ao filho mais do que o seio, o alento necessário para o apaziguamento da angústia do bebê, por ter se separado do corpo materno no nascimento. Assim, as dificuldades emocionais que interferem na capacidade de uma mulher amamentar o filho não a impedem de ser uma mãe zelosa e cuidadosa.

Desse modo, ressalta-se o cuidado que os profissionais devem ter em não culpar as mães que não conseguem aleitar, evitando discursos fundamentados em explicações científicas que foquem apenas na transmissão objetiva de informações sobre as vantagens da alimentação ao seio, pois o sentimento de culpa só dificultará sua relação com o bebê.

É importante que a equipe atenda a díade mãe-bebê compreendendo as peculiaridades decorrentes do nascimento prematuro, para que não sejam levantados pré-julgamentos acerca do modo considerado "adequado" de ser mãe pela cultura e sociedade em que vivemos. Não obstante, deve-se evitar a cristalização da fantasia que muitas mães têm de serem incapazes de tocar e nutrir os seus filhos. Caso contrário, o sentimento de que são perigosas e estão sendo punidas pela separação precoce pode se confirmar, fazendo com que reproduzam a situação infantil de que somente os seus próprios pais podiam conceber e dar a vida, transferindo para a equipe médica e de enfermagem a responsabilidade de cuidar do bebê.

A aposta do olhar psicanalítico sobre essa questão é que se possa retirar das sombras o que na clínica médica era considerado fonte de imprecisão, ou seja, a subjetividade e a constituição do sujeito. O discurso da mãe não deve ser desqualificado, pois isso afeta o seu narcisismo e a remete à angústia. A escuta psicanalítica das mães de bebês prematuros pode fazer surgir um sujeito desejante vivo, que está vivenciando uma condição traumática. De acordo com Rosa (2016), esse tipo de escuta tem efeito estruturante e organizador. Não se trata de qualquer escuta, mas de uma “. . . escuta metódica, atenta ao detalhe, à pequena incongruência, ao deslize, à repetição ou à ruptura da fala. Flutuante e aberta a interrupções, insistências e silêncios do discurso" (Dunker, 2011, p. 439).

A amamentação não deve significar uma sentença dolorosa a ser cumprida pela mãe, mas uma possibilidade de estabelecer com o bebê uma relação única de intimidade, que contribuirá para o fortalecimento de laços afetivos que são construídos desde o nascimento e se desenvolverão ao longo da vida. 


\section{Referências}

Agman, M., Druon, C., \& Frichet, A. (1999). Intervenções psicológicas em neonatologia. In D. B. Wanderley (Ed.), Agora eu era o rei: Os entraves da prematuridade (pp. 17-34). Salvador: Ágalma.

Arias, M. I. (2018). A escuta do indizível. In A. Jerusalinsky (Ed.), Psicanálise e desenvolvimento infantil: Um enfoque transdisciplinar (6a ed.) (pp. 294-298). Porto Alegre: Artes e Ofícios.

Badinter, E. (1985). Um amor conquistado: O mito do amor materno. Rio de Janeiro: Nova Fronteira.

Baeta, M. L. M. (2011). Função paterna na UTI neonatal: o empuxo à mãe diante do encontro traumático com o mais além do pai. In G. Batista, M. D. Moura \& S. B. Carvalho (Orgs.), Psicanálise e hospital: A responsabilidade da Psicanálise diante da ciência médica (pp. 157-170). Rio de Janeiro: Wak Editora.

Baltazar, D. V. S., Gomes, R. F. S., \& Cardoso, T. B. D. (2010). Atuação do psicólogo em unidade neonatal: Construindo rotinas e protocolos para uma prática humanizada. Revista da SBPH, 13(1), 1-18. Recuperado de http://pepsic.bvsalud.org/scielo. php?script=sci_arttext\&pid=S1516-08582010000100002\&lng=pt\&tIng=pt

Braga, N. A., \& Morsch, D. S. (2003). Os primeiros dias na UTI. In M. E. L. Moreira (Org.), Quando a vida começa diferente: O bebê e sua família na UTI neonatal (pp. 51-68). Rio de Janeiro: Fiocruz.

Brasil. Ministério da Saúde. (2006). Pré-natal e Puerpério: Atenção qualificada e humanizada (3a ed.). Brasília-DF: Ministério da Saúde. Recuperado de http://bvsms.saude.gov.br/bvs/ publicacoes/manual_pre_natal_puerperio_3ed.pdf

Brasil. Ministério da Saúde. (2009). Norma de atenção humanizada ao recém-nascido de baixo peso: Método-canguru (2a ed.). Brasília-DF: Ministério da Saúde.

Brazelton, T. B. (1994). Momentos decisivos do desenvolvimento infantil. São Paulo: Martins Fontes.

Bruschweiler-Stern, N. (1997). Mère à terme et mère prématuré. In M. Dugnat (Org.), Le monde relationnel du bébé (pp. 19-24). Ramonville-Saint-Agne: Érès.

Carvalho, M. R., \& Tavares, L. A. M. (2010). Amamentação: Bases científicas (3a ed.). Rio de Janeiro: Guanabara Koogan.

Couronne, M. (1997). O prematuro: um bebê inteiro à parte. In M. C. Busnel (Org.), A linguagem dos bebês: Sabemos escutá-los? (pp. 136-145). São Paulo: Escuta.

Dolto, F. (2007). As etapas decisivas da infância (2a ed.). São Paulo: Martins Fontes. (Originalmente publicado em 1950).

Dunker, C. I. L. (2011). O nascimento da clínica. In C. I. L. Dunker (Ed.), Estrutura e constituição da clínica psicanalítica: Uma arqueologia das práticas de cura, psicoterapia e tratamento (pp. 389-481). São Paulo: Annablume.

Fabre-Grenet, M. (1997). Os meios de comunicação do prematuro. In M. C. Busnel (Org.) A linguagem dos bebês: Sabemos escutá-los? (pp. 111-123). São Paulo: Escuta.

Feliciano, D. S., \& Souza, A. S. L. (2011). Para além do seio: uma proposta de intervenção psicanalítica pais-bebê a partir de dificuldades na amamentação. Jornal de Psicanálise, 44(81), 145-161. Recuperado de http://pepsic.bvsalud.org/scielo. php?script=sci_arttext\&pid=S0103-58352011000200012\&lng=pt\&tIng=pt 
Fiori, W. R. (1981). Organização afetiva inicial: fase oral e amamentação. In C. R. Rappaport, W. R. Fiori \& E. Herzberg, E (Orgs.), Psicologia do Desenvolvimento (Vol. 2, pp. 29-43). São Paulo: EPU.

Freitas, A. L. L. P, \& Gutierrez, D. M. D. (2010). Possibilidades de intervenção do psicólogo em unidades de terapia intensiva neonatal (UTINS) com bebês pré-termos e seus familiares. Revista Amazônica, 5(2), 182-196. Recuperado de https://tede.ufam.edu.br/handle/ tede/3935

Gandra, M. I. S. (1998). A Psicologia na Unidade de Neonatologia. In V. A. Angerami-Camon (Org.), Urgências psicológicas no hospital (pp. 81-99). São Paulo: Pioneira.

Góes, A. D. C. (1999). Avaliação de questões relacionadas ao atendimento da equipe em uma Unidade de Cuidados Intensivos Neonatais sob a perspectiva dos pais após a alta. In D. B. Wanderley (Ed.), Agora eu era o rei: Os entraves da prematuridade (pp. 83-104). Salvador: Ágalma.

Gorgulho, F. R., \& Pacheco, S. T. A. (2008). Alimentação de prematuros em uma unidade neonatal. Escola Anna Nery Revista de Enfermagem, 12(1), 19-24. doi:https://dx.doi. org/10.1590/S1414-81452008000100003

Harlow, H. F., \& Suomi, S. J. (1970). The nature of love: Simplified. American Psychologist 2, 161-168.

laconelli, V. (2011). Vamos refletir? [Blog]. Recuperado de https://mamamiaamamentar. wordpress.com/tag/bebe/

Klaus, M. H., \& Kennell, J. H. (1992). Pais/Bebês: A formação do apego. Porto Alegre: Artes Médicas.

Klaus, M. H., Kennell, J. H. \& Klaus, P. H. (2000). Vínculo: Construindo as bases para um apego seguro. Porto Alegre: Artes Médicas.

Lacan, J. (1998). Escritos. Rio de Janeiro: Jorge Zahar. (Originalmente publicado em 1966).

Langer, M. (1981). Maternidade e sexo: Estudo psicanalítico e psicossomático. Porto Alegre: Artes Médicas.

Lebovici, S. (1987). O bebê, a mãe e o psicanalista. Porto Alegre: Artes Médicas.

Lima, L. A. (2008). Intervenção precoce em neonatologia. In E. S. N. Lange (Org.), Contribuições à psicologia hospitalar: Desafios e paradigmas (pp. 129-44). São Paulo: Vetor.

Maldonado, M. T. (2017). Psicologia da gravidez: Gestando pessoas para uma sociedade melhor. São Paulo: Ideias \& Letras.

Mathelin, C. (1999). O sorriso da Gioconda: Clínica psicanalítica com os bebês prematuros. Rio de Janeiro: Companhia de Freud.

Mazet, P., \& Stoleru, S. (1990). Manual de psicopatologia do recém-nascido. Porto Alegre: Artes Médicas.

Middlemore, M. P. (1974). Mãe e filho na amamentação: Uma analista observa a dupla amamentar. São Paulo: Ibrex.

Morsch, D. S., \& Braga, M. C. N. A. (2007). À procura de um encontro perdido: O papel da "preocupação médico-primária" em UTI neonatal. Revista Latinoamericana de Psicopatologia Fundamental, 10(4), 624-636. doi:https://dx.doi.org/10.1590/ S1415-47142007000400005

Rosa, M. D. (2016). A clínica psicanalítica em face da dimensão sociopolítica do sofrimento. São Paulo: Escuta. 
Soares, J. P. O., Novaes, L. F. G., Araújo, C. M. T., \& Vieira, A. C. C. (2016). Amamentação natural de recém-nascidos pré-termo sob a ótica materna: Uma revisão integrativa. Revista CEFAC, 18(1), 232-241. doi:https://dx.doi.org/10.1590/1982-021620161819215

Souza, N. L., Araújo, A. C. P. F., Costa, I. C. C., Carvalho, J. B. L., \& Silva, M. L. C. (2009). Representações de mães sobre hospitalização do filho prematuro. Revista Brasileira de Enfermagem, 62(5), 729-33. doi:https://dx.doi.org/10.1590/S0034-71672009000500013

Stern, D. N. (1997). A constelação da maternidade: O panorama da psicoterapia pais/bebê. Porto Alegre: Artes Médicas.

Wilheim, J. (1997). O que é psicologia pré-natal? São Paulo: Casa do Psicólogo.

Winnicott, D. W. (1978). Textos selecionados: Da pediatria à psicanálise. Rio de Janeiro: Francisco Alves.

Winnicott, D. W. (1983). O ambiente e os processos de maturação: Estudos sobre a teoria do desenvolvimento emocional. Porto Alegre: Artmed.

Winnicott, D. W. (1999). Os bebês e suas mães. São Paulo: Martins Fontes.

Winnicott, D. W. (2017). A criança e o seu mundo (6a ed.). Rio de Janeiro: Livros Técnicos Científicos Editora.

Zornig, S. M. A. J., Morsch, D. S. M., \& Braga, N. A. (2004). Parto Prematuro: Antecipação e Descontinuidade Temporal? In R. O. Aragão (Org.), O bebê, o corpo e a linguagem (pp.165174). São Paulo: Casa do Psicólogo.

Recebido em: 23/11/2019

Última revisão: $13 / 02 / 2020$

Aceite final: $31 / 03 / 2020$

Sobre as autoras:

Andréa Leão Leonardo-Pereira de Freitas: Doutoranda em Psicologia Clínica e Cultura na Universidade de Brasília (UnB). Mestre em Psicologia pela Universidade Federal do Amazonas (UFAM). E-mail: leao.freitas@uol.com.br, ORCID: https://orcid.org/0000-0001-8969-654X

Eliana Rigotto Lazzarini: Doutora em Psicologia Clínica e Cultura pela Universidade de Brasília (UnB). Atualmente é professora do departamento de Psicologia Clínica na UnB. E-mail: elianalazzarini@gmail.com, ORCID: https://orcid.org/0000-0002-6740-5059

Eliane Maria Fleury Seidl: Doutora em Psicologia pela Universidade de Brasília (UnB). Atualmente é professora do departamento de Psicologia Clínica na UnB. E-mail: eliane.seidl@gmail.com, ORCID: https://orcid.org/0000-0002-1942-5100 